\title{
НАУКА О ЛЕКАРСТВЕННЫХ ШЛЯПОЧНЫХ ГРИБАХ: СОВРЕМЕННЫЕ ПЕРСПЕКТИВЫ, ДОСТИЖЕНИЯ, ДОКАЗАТЕЛЬСТВА И ВЫЗОВЫ С.П. Вaccep
}

Институт ботаники им. Н.Г. Холодного Национальной академии наук Украины, Киев, Украина

Эл.nочта: spwasser@research.haifa.ac.il

Статья поступила в редакцию 30.03.2015; принята к печати 19.05.2015

В обзоре представлены достижения, перспективы, проблемы и пути развития науки о лекарственных шляпочных грибах в XXI веке. Для лекарственных шляпочных и других макроскопических грибов известно около 130 фармакологических применений, включая противоопухолевое, иммуномодулирующее, антиоксидантное, связывающее свободные радикалы, кардиоваскулярное, снижающее холестерин в крови, противовирусное, антибактериальное, противопаразитное, противогрибковое, детоксифицирующее, гепатопротекторное и противодиабетическое действие. У базидиомицетов биологически активные вещества содержатся не только в плодовых телах, но также в мицелии и культуральной жидкости. Особое внимание в обзоре уделено грибным полисахаридам и вторичным метаболитам. Обобщены результаты исследований полисахаридов из примерно 700 видов высших гетеро- и гомобазидиомицетов. Описаны многочисленные выделенные из лекарственных грибов биологически активные полисахариды и полисахаридо-протеиновые комплексы, способные стимулировать иммунные реакции, а также обладающие выраженной противоопухолевой активностью. Механизм такого действия полностью не раскрыт, и в центре внимания находятся вопросы стимулирования и модуляции иммунного ответа этими соединениями. Некоторые из них прошли фазы I, II и III клинических испытаний, и широко и успешно применяются в Азии для лечения различных видов рака и других заболеваний. В обзоре также отмечены нерешенные вопросы исследования медицинского применения шляпочных грибов.

Ключевые слова: лекарственные грибы, антиоксидантная активность, полисахариды, $\beta$-глюканы, противоопухолевая активность, иммуномодулирующее действие, вторичные метаболиты.

\section{MEDICINAL MUSHROOM SCIENCE: CURRENT PROSPECTS, ADVANCES, EVIDENCES, AND CHALLENGES S.P. Wasser \\ N.G. Kholodny Institute of Botany, National Academy of Sciences of Ukraine (Kiev, Ukraine) E-mail:spwasser@research.haifa.ac.il}

The present review addresses the current prospects, advances, challenges, and future development of medicinal mushroom science in the $21^{\text {s }}$ century. A total of about 130 medicinal functions attributed to medicinal mushrooms and fungi include antitumor, immunomodulating, antioxidant, radical scavenging, cardiovascular, antihypercholesterolemic, antiviral, antibacterial, anti-parasitic, antifungal, detoxifying, hepatoprotective, and antidiabetic effects. Many, if not all, higher Basidiomycete mushrooms contain biologically active compounds in their fruit bodies, cultured mycelium, and culture broth. Special attention is paid to mushroom polysaccharides. Data onmushroom polysaccharides and different secondary metabolites are available for about 700 species of higher Hetero- and Homobasidiomycetes. Numerous bioactive polysaccharides or polysaccharide-protein complexes described from medicinal mushrooms are found to enhance the innate and cell-mediated immune responses and exhibit antitumor activities in animals and humans. Although the mechanism of their antitumor actions is still not completely understood, stimulation and modulation of host immune responses by these mushroom compounds is now under spotlight. Several of mushroom-derived compounds have passed Phase I, II, and III clinical trials and are now used extensively and successfully in Asia to treat various cancers and other diseases. Special attention is paid to important unsolved problems in studies of medicinal mushrooms.

Keywords: medicinal mushrooms, antioxidant activities, polysaccharides, beta-glucans, antitumor activity, immunomodulating activity, secondary metabolites.

\section{Введение}

Начало использования шляпочных и других макроскопических грибов в традиционной народной медицине датируется, по крайней мере, эрой неолита. Опыт человечества в отношении съедобности и лекарственного использования грибов формировался в течение тысячелетий.

Современные исследования проверили и документально подтвердили большую часть древних знаний о лекарственных шляпочных грибах (ЛШГ). В последние три десятилетия междисциплинарные научные исследования ЛШГ демонстрируют уникальные свойства веществ, выделенных из ряда видов грибов. Препараты грибного происхождения используются в современной клинической практике Японии, Китая, Кореи, России и некоторых других стран [1-4].

Древние восточные традиции подчеркивают важность некоторых видов шляпочных грибов, а именно - лингчи или рейши (Ganoderma lucidum (W. Curt.: Fr.) P. Karst.) и шиитаке (Lentinus edodes (Berk.) Singer). Шляпочные грибы также играли важную роль в лечении заболеваний в сельской местности восточноевропейских стран. Наиболее важными видами в этих странах являются Inonotus obliquus (Pers.: Fr.) Pilát (чага), Fomitopsis officinalis (Vill.: Fr.) Bond. et Singer (трутовик лекарственный), Piptoporus betulinus (Bull.: Fr.) P. Karst. (березовый трутовик) и Fomes fomentarius Fr.: Fr. (трутовик настоящий) $(4,5)$. Эти виды при- 
меняют для лечения желудочно-кишечных заболеваний, различных форм рака, бронхиальной астмы, ночной потливости и пр. Длительная история традиционного использования грибов в качестве лекарственных средств известна в Центральной Америке (особенно виды рода Psilocybe), Африке (племенами йоруба в Нигерии и Бенине), в арабских странах, например, Алжире и Египте. Хорошо известна особая роль мухомора красного (Amanita muscaria (L.: Fr.) Pers.) в сибирском и тибетском шаманизме, буддизме и обрядах кельтов $[1,2,4,6]$.

Шляпочные грибы сейчас оцениваются не только по их питательной ценности и биологической доступности, но и по фармакологическим свойствам. Они представляют собой огромный и в то же время нереализованный источник новых мощных фармацевтических продуктов. Чрезвычайно важным для современной медицины является то, что ЛШГ представляют собой неисчерпаемый источник полисахаридов (особенно $\beta$-глюканов) и полисахарид-протеиновых комплексов, обладающих противораковыми и иммуностимулирующими свойствами. Большинство, если не все, высшие базидиомицеты содержат много различных биологически активных высокомолекулярных и низкомолекулярных соединений (тритерпены, лактоны, алкалоиды и другие метаболиты) в плодовых телах, культивируемом мицелии и его культуральной жидкости [3, 4, 15-17].

В настоящее время ЛШГ используются как: А) диетическая пища (в 2012 г. мировое производство культивируемых грибов составило 30 миллионов тонн); Б) пищевые добавки (ПД) (быстрорастущий рынок грибных пищевых добавок на современном этапе оценивается более чем в 18 миллиардов долларов США ежегодно); В) источник нового класса лекарств, обозначаемых как «грибные фармацевтические средства»; Г) природные средства защиты растений, обладающие инсектицидной, фунгицидной, бактерицидной, гербицидной, противонематодной и антифитовирусной активностью; Д) косметические средства, ввиду того что косметические компании широко используют различные вещества ЛШГ, включая полисахариды, в частности, водорастворимые $\beta$-глюканы, глюкуроноксиломаннаны, сахахитин (sacchachitin), а также тирозиназу и другие ферменты для улучшения пленкообразующих свойств, активации эпидермального фактора роста, антиоксидантного, антиаллергического, антибактериального и противовоспалительного действия, стимуляции коллагеназной активности, ингибирования аутоиммунного витилиго и лечения акне $[3,4,7,8]$.

Лекарственные шляпочные грибы сопоставимы по значению с лекарственными растениями и могут быть определены как макроскопические грибы, главным образом, высшие базидиомицеты и некоторые аскомицеты, которые используются в виде экстрактов или порошков для профилактики, облегчения или лечения болезни и (или) для обеспечения сбалансированной здоровой диеты. Подобно определению «препараты из лекарственных растений» («herbal drugs»), высушенные плодовые тела, мицелий и споры могут рассматриваться как «препараты из лекарственных грибов» (mushroom drugs) или грибные препараты (fungal drugs). Аналогично термину «фитофармацевтические средства» или «растительные препараты», в данном случае могут использоваться термины «грибные фармацевтические средства» или «грибные препараты».

\section{Многообразие источников грибных лекарственных препаратов}

Грибы в целом и шляпочные грибы в частности чрезвычайно многочисленны, разнообразны и распространены повсеместно. В общем, согласно докладу двадцатилетней давности [9], принято считать, что существует 1,5 миллиона видов грибов. На сегодняшний день предлагается цифра в 3 миллиона видов [10], а по последним оценкам число видов грибов на Земле может превышать 5 миллионов. В то же время лишь 110000 видов грибов были описаны. Эти цифры основаны на экстраполяции числа видов, добавляемых в каждый род, указанный в последнем издании Словаря грибов (Dictionary of Fungi) [11], на протяжении предыдущих лет $[10,12,13]$, и включают организмы, традиционно изучаемые микологами: миксомицеты, хитридиомицеты, мицелиальные грибы, лихенообразующие грибы, плесневые грибы и дрожжи. На основании таких оценок можно считать, что шляпочные грибы представлены 16 тысячами видов из числа вошедших в издания Dictionary of Fungi предыдущих лет [11]. Предполагается, что число видов шляпочных грибов в мире насчитывает 150000-160000; и пока только $10 \%$ от названного числа известны науке [3, 9-11]. Из числа новых для науки грибов, каталогизированных в Index of Fungi за последние 10 лет, около $60 \%$ являются тропическими видами. Это также касается и шляпочных грибов, особенно видов, образующих эктомикоризу с местными деревьями. Но открывать новые виды продолжают и в Европе, и в Северной Америке. В различных тропических зонах 22-55\% (в некоторых случаях до $73 \%)$ видов грибов еще не описаны $[9-10,13]$. Реальное число видов грибов, существующих на Земле, может быть в 50 раз больше, чем цифры, основанные на текущих данных. Современные методы секвенирования ДНК предполагают, что существует, по крайней мере, 5 миллионов видов грибов [12]. Следовательно, при современных темпах - около 1200 новых видов в год, согласно данным за последние 10 лет [14], для описания этого биоразнообразия грибов потребуется более 4 тысяч лет. Сейчас известно около $1 \%$ всей мировой микобиоты и $10 \%$ мирового биоразнообразия шляпочных грибов $[3,4]$.

Специалисты по таксономии некоторых групп лекарственных шляпочных грибов хорошо знакомы с «общеизвестными» видами, однако некоторые из их биохимических и фармакологических особенностей остаются до настоящего времени неизвестными. С.П. Вассер представил обобщенные сведения о фармакологических свойствах примерно 700 из 2000 хорошо известных и безопасных видов [3]. Таким образом, сегодняшний уровень знаний оставляет огромный потенциал для изучения биоразнообразия лекарственных грибов.

\section{Современные достижения и перспективы}

Установлено, что грибы (ЛШГ и другие макромицеты) имеют около 130 фармакологических применений. Недавно изученные лекарственные свойства шляпочных грибов включают противоопухолевый, иммуномодулирующий, антиоксидантный, связывающий 
свободные радикалы, кардиоваскулярный, снижающий холестерин крови, противовирусный, антибактериальный, противопаразитарный, противогрибковый, детоксифицирующий, гепатопротекторный и антидиабетический эффекты. Лучше всего применять препараты из ЛШГ и грибные пищевые добавки для предотвращения и лечения нарушений иммунитета, особенно ослабленного иммунитета и иммунодефицитов. Препараты из ЛШГ также полезны для онкологических больных после курсов химио- или радиотерапии в связи с различными типами опухолей, при хронических вирусных заболеваниях крови (гепатиты $\mathrm{B}, \mathrm{C}$ и D), различных типах анемий, при ВИЧ-инфекции, заболеваниях ВИЧ и СПИДе, при инфицировании вирусами герпеса и вирусом Эпштейна-Барр, при синдроме хронической усталости, для пациентов с хроническим гастритом и язвой желудка, вызванной Helicobacter pylori, для больных деменцией (особенно с болезнью Альцгеймера) [3, 4, 18-20].

Грибные полисахариды предотвращают онкогенез, оказывают прямое противоопухолевое действие, предотвращают образование метастазов. Их действие особенно эффективно в сочетании с химиотерапией. Противоопухолевые эффекты полисахаридов опосредованы главным образом Т-зависимыми иммунными реакциями при участии цитотоксических макрофагов, моноцитов, нейтрофилов, клеток-киллеров, дендритных клеток и химических мессенджеров (цитокинов, интерлейкинов, интерферонов и колониестимулирующих факторов), а также системой комплемента и белками острой фазы иммунного ответа. Кроме того, полисахариды ЛШГ способны индуцировать экспрессию генов различных иммуномодулирующих цитокинов и их рецепторов [3, 21-25].

Рак - это общий термин, включающий сотни различных типов заболеваний, признаки которых выявляются даже при анализе черепов неандертальцев (35 тыс. лет до н. э.) и египетских и инкских мумий [26]. По оценкам глобального бремени рака в настоящее время [27] число случаев заболевания раком возросло с 12,7 млн в 2008 г. до 14,1 млн в 2012 г. Среди основных неинфекционных болезней: сердечно-сосудистых, хронического диабета, респираторных и рака - за последние несколько лет рак становится основной причиной смерти на национальном, региональном и глобальном уровнях [27]. Предполагается, что в этом году общее число новых случаев заболевания раком составит 40 млн. По оценке ВО3, 84 млн человек умрет от рака в период 2005-2015 гг. Рак убивает больше людей, чем СПИД, малярия и туберкулез вместе взятые. Более того, в Китае и Индии (наиболее густонаселенные страны) также возрастает смертность от рака, в большой степени обусловленная курением, питанием и экологическими проблемами. В глобальных масштабах, по оценке ВО3, ожидаемая смертность от рака в 2030 г. достигнет 17 млн человек в год [27].

Препараты из лекарственных грибов и полисахариды ЛШГ показывают положительные результаты в лечении опухолей in vitro и in vivo. Новый класс противоопухолевых грибных лекарственных препаратов был назван модификаторами биологического ответа (МБО). МБО используются в сопроводительной терапии при лечении рака, наряду с хирургией, химиотерапией и радиотерапией $[3,4,23-25,28]$. Главная проблема при лечении онкологических заболеваний, особенно при химиотерапии и радиотерапии, - повреждение или ослабление природных иммунологических реакций пациента. Применение грибных МБО в лечении онкологических заболеваний сфокусировано на улучшении качества жизни больных ввиду того, что они уменьшают побочные эффекты и помогают подавить рост опухоли. Большинство из этих препаратов активируют природные иммунные ответы организма и могут использоваться как поддерживающая терапия и для профилактики рака.

Иммуномодулирующие вещества, выделенные из более чем 30 видов лекарственных грибов, показали противоопухолевую активность в лечении животных. Однако лишь немногие из них были протестированы на их противораковую активность применительно к человеку. Некоторые из протестированных препаратов представляют собой $\beta$-d-глюканы или комплексы $\beta$-d-глюканов с белками. Последние демонстрируют значительно большую иммунопотенциирующую активность, чем свободные глюканы. Проведено несколько клинических испытаний, подтвердивших ингибирующий рост опухолей эффект препаратов из Lentinus edodes [21, 23, 29], Grifola frondosa (Dicks.: Fr.) Gray [30, 31], Schizophyllum commune Fr.: Fr. [24, 32], Ganoderma lucidum [33, 34], Trametes versicolor (L.: Fr.) Lloyd [35], I. obliquus [36, 37], Phellinus linteus (Berk. et M.A. Curt.) Teng [38], Flammulina velutipes (W. Curt.: Fr.) Singer [39], Hypsizygus marmoreus (Peck) Bigel. [40], Ophiocordyceps (=Cordyceps) sinensis (Berk.) G.H. Sung et al. [41], Agaricus brasiliensis $\mathrm{S}$. Wasser et al. (=Agaricus blazei sensu Heinem.) [42, 43] и Tremella mesenterica Retz.: Fr. $[19,44]$. Действие грибных иммуномодулирующих средств включает активацию дендритных клеток, естественных киллеров, Т-клеток, макрофагов и выработку цитокинов. Некоторые фармакологические вещества из лекарственных грибов, главным образом, полисахариды (особенно $\beta$-глюканы), были доработаны до коммерческих препаратов для клинического применения: Крестин (PSK) и PSP (полисахаридпептид) из T. versicolor; Лентинан, изолированный из L. edodes; Шизофиллан (Сонифилан, Шизофиран, или SPG) из Sch. commune; Бефунгин - из I. obliquus; D-фракция - из G. frondosa; GLPS-полисахаридная фракция из G. lucidum; активное соединение, связанное с гексозой (АНCС) и изолированное из L. edodes, и многие другие.

Среди других грибных компонентов, представляющих терапевтический интерес, следует отметить вторичные метаболиты, особенно низкомолекулярные компоненты, такие как лактоны, терпеноиды и алкалоиды, антибиотики различного химического строения, хелаторы ионов металлов, которые тоже могут влиять на иммунитет. Лекарственные грибы также содержат множество ферментов, таких как лакказа, супероксиддисмутаза, глюкозоксидазы и пероксидазы. Было показано, что ферментная терапия играет важную роль в лечении рака путем предотвращения окислительного стресса и ингибирования клеточного роста $[3,16]$.

Для многих грибов уже известны метаболиты, способные модулировать конкретные внутриклеточные процессы, играющие роль в лечении онкологических заболеваний $[3,4,16,45-50]$. Например, фенилэтиловый эфир кофейной кислоты (САРE) из Agaricus bisporus (J.E. Lange) Imbach и Marasmius oreades 
(Bolt.) Fr., L. edodes и Ph. linteus, активирует В-клетки, специфически ингибируя связывание ядерного фактора каппа-B (NF-кпорошок из культивируемых плодовых тел, водные или спиртовые экстракты этих плодовых тел;

сушеные и измельченные препараты из сочетания субстрата, мицелия и грибных примордиев;

биомасса или экстракты из мицелия, полученного методом глубинного культивирования в ферментерах или биореакторах;

высушенные плодовые тела дикорастущих грибов в виде капсул или таблеток;

споры и их экстракты.

Возросший интерес к традиционным методам лечения различных физиологических нарушений и признание многочисленных биологических эффектов у грибных продуктов привели к возникновению термина «грибные нутрицевтики», который не следует путать с нутрицевтиками, функциональной пищей и «фармацевтиками». Грибные нутрицевтики это очищенные или частично очищенные экстракты или сухая биомасса грибного мицелия или плодового тела, которые используются в виде капсул или таблеток в качестве пищевой добавки (не заменяющей пищи) и имеют потенциальное терапевтическое применение. Их регулярное употребление может улучшить иммунитет и сопротивляемость болезням и, в некоторых случаях, вызвать регрессию болезненного состояния.

Продукты на основе ЛШГ являются прекрасными диетическими добавками. Быстрорастущий рынок грибных ПД оценивается в 18 млрд долларов США (представляя 10\% всего рынка БАД). С каждым годом растет объем новых данных о благоприятных эффектах пищевых добавок из ЛШГ [4]. В настоящее время на рынке доступен новый продукт из ЛШГ для лечения деменций (особенно болезни Альцгеймера), разработанный из стандартизованных экстрактов, содержащих герициноны и амилобан (оба компонента выделены из гриба Hericium erinaceus - «львиная грива»). Общая стоимость пищевых добавок только из Ganoderma, Ophiocordyceps и Cordyceps составляет более 4 млрд долларов США в год.

\section{Достижения и нерешенные проблемы}

С одной стороны, наука о ЛШГ за последние тридцать лет совершила гигантский прорыв и признана действительно успешной новой отраслью современной науки.

Были разработаны новые классы лекарств и различные типы продуктов из ЛШГ.

Был создан единственный в данной отрасли журнал - Международный журнал лекарственных грибов (International Journal of Medicinal Mushrooms, издательство Begell House, США).

Раз в два года проводится Международная конференция по лекарственным грибам, следующая (восьмая по счету) состоится в августе 2015 г. в Колумбии. Новое Международное общество по ЛШГ зарегистрировано в 2013 г. в Канаде.

Опубликованы результаты около 400 клинических испытаний с использованием ЛШГ в лечении различных заболеваний. До настоящего времени по данной теме опубликовано более 50 тысяч статей и получено около 15 тысяч патентов, касающихся различных аспектов исследований ЛШГ. С 2005 г. ежегодно ре- гистрируется 250-350 патентов для G. lucidum [51]. Тайванские ученые, например, получили более 100 патентов на один из видов рода Antrodia.

С другой стороны, есть ряд нерешенных, очень серьезных проблем в будущем науки о ЛШГ, которые, в свою очередь, могут повлиять на ее развитие в XXI веке. Ниже приведены наиболее значимые проблемы в развитии науки о ЛШГ.

\section{Таксономия и номенклатура}

Отец биологической номенклатуры, профессор К. Линней 300 лет назад написал "Nomina si nescis, perit et cognito rerum” («Если не знаешь названия вещи, невозможно познать ее суть»).

Идентификация многих видов ЛШГ нуждается в критической обработке. Без верного научного названия ЛШГ их будущие исследования не будут действительными и, соответственно, не будут иметь ценности. Наряду с классическими таксономическими методами, удобным и полезным для правильной идентификации видов ЛШГ и стандартизованных продуктов из них может быть такой молекулярный метод, как ДНК-штрихкодирование (DNA barcoding). Например, в настоящее время стало очевидным, что значительная часть образцов, ранее определенных в большинстве фармакологических исследований как лингчи, или рейши (G. lucidum), были идентифицированы неверно. Ganoderma lucidum представляет собой таксон-линнеон или комплекс видов, будущее разграничение которого нуждается в осторожном подходе [52]. Публикации, патенты и продукты также находятся «в группе риска». За все время в мире были описаны, по крайней мере, 166 видов рода Ganoderma [53]. Около сотни видов рода Ganoderma известны из Китая $[54,55]$. До сих пор, например, не известно таксономическое положение так называемого медицинского голубого лингчи, красного или белого лингчи.

Следует отметить еще один важный момент: опубликованы данные, согласно которым так называемый G. lucidum из Китая представляет собой нечто совершенно иное, чем G. lucidum, найденный и описанный в Европе. Поэтому был введен новый для микобиоты Китая вид - Ganoderma lingzhi Sheng H. Wu, Y. Cao et Y.C. Dai. Это привело к еще большим проблемам и путанице. Кто может с уверенностью сказать, какой именно вид рода Ganoderma является лекарственным? Какой вид лингчи является китайским национальным грибом - G. lucidum или G. lingzhi? Янг и Фенг опубликовали специальный мини-обзор, посвященный этой проблеме: «Что такое китайский лингчи?» [56]. Молекулярно-филогенетическое исследование, основанное на ITS (internal transcribed spacer) и 25S-рибосомальных последовательностях ДНК, свидетельствуют о том, что большинство образцов, определяемых как G. lucidum из Восточной Азии, не конспецифичны с G. lucidum, найденной в Европе [56].

В 2012 г. группой китайских ученых были опубликованы данные о геномной последовательности модельного лекарственного гриба G. lucidum [57]. Авторами было определено, что размер генома G. lucidum составляет 43,3 Mb (миллионов пар оснований), и, по результатам анализа нуклеотидных последовательностей, этот геном содержит 16133 генов. Данные были получены с использованием нового поколения методов секвенирования и оптических методов 
анализа. Однако этот очень важный результат не решает проблемы комплекса видов G. lucidum ввиду того, что был изучен один дикариотический штамм CGMCC5.0026, принадлежащий азиатской группе G. lucidum из Китая, который был объявлен новым для науки видом - G. lingzhi.

Пример ошибочной идентификации был продемонстрирован для Agaricus blazei - хорошо известного по литературным данным лекарственного гриба. Agaricus blazei - эндемичный для Северной Америки вид, описанный только из трех локалитетов и не существующий в культуре, ввиду чего он не может быть отнесен к лекарственным видам. Имеются две различные точки зрения по поводу этого вида: A. blazei sensu Murrill, известен из трех локалитетов в США, и A. blazei sensu Heinem., известен из Бразилии и культивируется в Японии $[42,43]$. Мы изучили типовой материал A. blazei sensu Murrill, A. blazei sensu Heinem. и A. subrufescens из Нью-Йоркского ботанического сада, наряду с другими видами этой группы-как штаммы, культивируемые в разных странах, так и природный материал из Бразилии. Оказалось, что A. blazei sensu Murrill и A. blazei sensu Heinem. представляют собой два разных вида.

A. blazei sensu Murrill отличается от A. blazei sensu Heinem. размером и формой плодовых тел, поверхностью шляпки, типом шляпочных покровов, наличием хейлоцистид и размером спор. Было установлено, что широко культивируемый съедобный и лекарственный вид, известный как A. blazei, не имеет ничего общего с A. blazei, описанным Мурриллом из США, поэтому он был описан как новый для науки вид A. brasiliensis $[42,43]$. В настоящее время A. blazei не рассматривается как съедобный лекарственный вид. Позже с помощью морфологических и молекулярно-биологических исследований было подтверждено различие между A. blazei и A. brasiliensis [43]. Результаты П. Керригана [58] и наши данные [42, 43, 59], представленные в нескольких публикациях последних лет, прояснили различия между A. brasiliensis, A. subrufescens, A. fiardii, A. praemagniceps и A. blazei. В настоящее время эти виды классифицированы по четким морфологическим, молекулярным и биологическим признакам и различному географическому распространению. Таким образом, ошибочная классификация A. blazei, создавшая много проблем в науке о лекарственных грибах, к настоящему времени исправлена. Также хотелось обратить внимание на неправильное использование названия $A$. blazei для лекарственного и съедобного гриба - королевского шампиньона (Royal Sun Agaricus), гимематсутаке (японское название). Следует повторить, что A. blazei не является лекарственным грибом, этот вид не культивируется и известен только из трех местообитаний в США. В то же время, к сожалению, во многих публикациях, включая и китайские, ученые продолжают использовать для королевского шампиньона неправильное название $A$. blazei вместо A. brasiliensis.

Исследование съедобных лекарственных иляпочных грибов в чистой культуре

Следует уделять больше внимания исследованию съедобных ЛШГ в чистой культуре. Изучение культур необходимо для обеспечения стабильности и преемственности научной работы. Телеоморфная стадия является самым главным критерием в иден- тификации культур, однако довольно часто ЛШГ не образовывают плодовые тела в чистой культуре. В специальной микологической литературе слишком мало внимания уделено вегетативной стадии ЛШГ. Много видов ЛШГ невозможно правильно идентифицировать без изучения вегетативной стадии. Вегетативный мицелий культур ЛШГ представляет собой комплекс ветвящихся гиф, отличающихся только в узких пределах шириной, длиной, числом ядер, толщиной клеточной стенки и разветвленностью. Обобщение данных исследований вегетативного мицелия обеспечит новый материал для изучения и сравнения морфологических характеристик мицелия для потенциальной оценки его использования в вопросах таксономии и контроля чистоты в биотехнологических процессах $[3,4,60]$. Так как нет типовых штаммов ЛШГ, нам самим необходимо выбрать правильно идентифицированные типовые штаммы для многих видов ЛШГ. Необходимо организовать Всемирную коллекцию съедобных ЛШГ с депозитарной деятельностью, основанной на процедурах патентования согласно Будапештскому Договору. Данную проблему следует обсудить с Всемирной федерацией коллекций культур.

Проблемы пищзевых добавок из лекарственных шляпочных грибов

В последние годы возросла популярность производства грибной биомассы или различных экстрактов в виде пищевых добавок, функциональных продуктов и новых пребиотиков (нерастворимых $\beta$-d-глюканов). Наиболее важными вопросами, возникающими при создании пищевых добавок и функциональных продуктов, являются их безопасность, стандартизация, регулирование, эффективность и механизм действия.

К сожалению, надо признать, что во всем мире стандартизация пищевых добавок из ЛШГ находится на самых ранних этапах становления, учитывая и недостаточное понимание биоактивных эффектов этих добавок. До настоящего времени не существует международно признанных стандартов и протоколов для производства и тестирования продуктов из ЛШГ. Только соблюдение таких стандартов и протоколов может гарантировать качество продукта. Без соблюдения необходимого качества продуктов из ЛШГ доступные коммерческие препараты ЛШГ будут совершенно различными и будут колоссально отличаться по составу и эффективности. Не известно, вызваны ли биологически активные эффекты каким-либо единственным компонентом или синергетическим воздействием нескольких составляющих. Недостаточно данных о том, какие компоненты имеют лучший эффект - полученные из плодовых тел или из культивируемого мицелия. Являются ли просто высушенные плодовые тела и грибной порошок столь же эффективными, как и водные, спиртовые и спиртово-водные экстракты? Каковы различия между сырыми экстрактами и изолированными фракциями, какие из них являются более эффективными и более безопасными (некоторые компании продают D-фракцию G. frondosa маитаке, или GLPS-фракции G. lucidum). Роль низкомолекулярных соединений экстрактов ЛШГ также до сих пор не ясна.

Что является более эффективным - сочетание компонентов, содержащихся в биомассе или экстрактах 
из 2-10 различных видов лекарственных грибов в одной капсуле, или же только один вид ЛШГ в ней? Как оценить эффективность различных грибных компонентов в таком «сборном» грибном продукте (эффект «дробовика»)?

Так как грибные продукты могут быть стимуляторами цитокинов, возникает вопрос о возрасте ребенка, с которого возможно их безопасное назначение, поскольку иммунная система детей еще недостаточно сформирована.

Данные об используемых дозах противоречивы. Предлагаемые дозировки сильно различаются в зависимости от форм и составов. Многочисленные клинические исследования подтверждают, что 6 капсул (по 3 капсулы два раза в день, или по 2 капсулы трижды в день) по 500-1000 мг каждая (биомасса, сухой порошок или экстракт), являются принятой дозировкой препаратов ЛШГ. Согласно традиционной китайской медицине (ТКМ), стандартная доза сушеных плодовых тел или биомассы ЛШГ в день в различном виде (таблетки, капсулы, жидкие экстракты) должна быть эквивалентна приблизительно 100-150 г свежего грибного продукта.

Какие дозировки безопасны и эффективны при беременности и кормлении грудью? Отсутствие стандартов и недостаточно четко сформулированные рекомендации по использованию грибных добавок из ЛШГ, их точных дозировок и длительности применения свидетельствуют о необходимости очень серьезных исследований. Некоторые исследования показали, что передозировка может привести к иммунносупрессии, а слишком низкие дозы могут вообще «не запустить» иммунный ответ.

Самые большие проблемы, связанные с грибными пищевыми добавками, обусловлены их чрезвычайным разнообразием и отсутствием в настоящее время стандартов производства и протоколов тестирования, необходимых для гарантии качества продукции. Активные ингредиенты (действующее начало) многих ныне существующих коммерческих продуктов не идентифицированы.

В связи с отсутствием стандартов производства и контроля качества коммерчески доступные грибные препараты из одних и тех же видов и штаммов грибов значительно отличаются по составу и эффективности. Фальсификация продуктов из ЛШГ за счет похожих или ложных видов (например, различных видов рода Ganoderma вместо G. lucidum, видов рода Stereum вместо Trametes versicolor, и даже различных анаморфных видов рода Cordyceps вместо Ophiocordyceps sinensis) является достаточно распространенным явлением.

Существуют определенные трудности в производстве чистых $\beta$-глюканов для рынка (90-95\% $\beta$-глюканов на рынке - контрафактные, или поддельные). Использование фальсифицированных препаратов может привести к различным нежелательным эффектам [3, 4, 61].

Таким образом, до сих пор существуют неразрешенные проблемы, касающиеся безопасности некоторых хорошо известных продуктов ЛШГ. Например, исследования воздействия полисахаридных фракций G. frondosa на больных раком груди на стадиях I-II показали, что маитаке обладает комплексным эффектом, который может как подавлять, так и усиливать иммунную функцию [62].
Какова роль употребления свежих грибов? Было показано, что употребление свежих грибов может, например, привести к появлению анти- $\beta$-глюкановых антител в сыворотке крови человека. Группа Н. Оно из Японии подтвердила, что потребление свежих грибов может обеспечить лучшую защиту организма от патогенных грибов [63].

\section{Натуральные продукты из лекарственных шляпочных грибов - невостребованный источник открытия новых лекарств}

Получение существующих иммуномодулирующих и противораковых лекарств из полисахаридов ЛШГ (таких как Лентинан, Шизофиллан и Крестин) трудоемкий и дорогостоящий процесс, так как используются высокомолекулярные вещества [23, 24]. Все препараты из ЛШГ были разработаны на основе полисахаридов с высоким молекулярным весом, от 100 до 500 кДа. Эти вещества невозможно синтезировать, более того, их производство ограничивается экстракцией из плодовых тел, культивируемого мицелия, или культуральной жидкости. Такой подход диктует высокие рыночные цены. На сегодняшний день науке целесообразно сосредоточиться на исследовании благоприятных эффектов низкомолекулярных веществ, продуцируемых ЛШГ (так называемые низкомолекулярные вторичные метаболиты, действующие на апоптоз, ангиогенез, метастазирование, клеточный цикл и каскадную передачу сигналов в клетках) [16]. Западные фармацевтические компании более заинтересованы в относительно легко синтезируемых веществах, которые можно производить для рынка.

Исторически сложилось так, что большинство новых лекарств было получено из натуральных продуктов (вторичных метаболитов). ЛШГ - невостребованный источник для открытия новых лекарств. К 1990 г. около 80\% лекарств были либо природного происхождения, либо их дериватами. «Блокбастеры лекарств», такие как антибиотики (пенициллин, тетрациклин и эритромицин), противопаразитные средства (авермиктин), антималярийные препараты (хинин, артемизин), а также препараты, регулирующие липидный обмен (ловастатин и его аналоги), иммуносупрессанты для трансплантации органов (циклоспорин, рапамицины), противораковые лекарства (таксол, доксорубицин) совершили переворот в медицине [64]. Многие из вышеперечисленных лекарств были открыты и выделены из грибов.

Современные фармацевтические тенденции в профилактике рака включают разработку лекарств со следующими свойствами: А) ингибиторы ростовых факторов раковых клеток (такие лекарства, как герцептин, эрбитукс и терсева), блокирующие связывание раковых клеток с белками, которые способствуют их делению и росту; Б) блокаторы гормонов (такие препараты, как тамоксифен, удерживающий путем связывания с эстрогеновыми рецепторами клетку от деления); В) блокаторы внутриклеточные сигналов, нарушающие коммуникацию между энзимами, регулирующими рост и развитие; Г) ингибиторы ангиогенеза (например, авастин был первым препаратом, ингибирующим образование новых кровеносных сосудов вокруг раковых клеток и лишающим их питания) [65]. Около 900 противораковых лекарств были 
тестированы на человеке. Это число более чем в два раза превышает число экспериментальных препаратов для лечения болезней сердца и инсультов вместе взятых, приблизительно в два раза превышает число лекарств от СПИДа и всех остальных инфекционных заболеваний вместе взятых и почти в два раза превышает количество препаратов для лечения болезни Альцгеймера и других неврологических заболеваний [66]. Согласно исследованиям IMS Health, противораковые препараты составляют наиболее продаваемую категорию лекарств (в мире - с 2006 г., а в США - с 2008 г.). На сегодняшний день фармакологические компании видят свое будущее в создании препаратов для лечения рака. Например, одна из крупнейших в мире фармакологических компаний Pfizer (США) в последние десятилетия была сфокусирована на разработке и производстве лекарств для сердечно-сосудистой системы, препаратов, снижающих уровень холестерина в крови (Липитор) [67] и снижающих кровяное давление (Норваск) [66]. Не так давно Pfizer приняла на работу около тысячи исследователей для разработки лекарства от рака - болезни, которую долгое время данная фармацевтическая компания игнорировала, - сократила разработку сердечно-сосудистых препаратов и сконцентрировалась на разработке противораковых лекарств как на одном из шести своих главных приоритетов. Около $20 \%$ расходов из более чем 7-миллиардного бюджета компании выделены на исследования и разработку противораковых лекарств, и уже 22 из сотни, находящихся в разработке, были протестированы как антираковые препараты [66].

Прогресс в исследованиях ЛШГ должен включать геномику, протеомику, метаболомику и системную фармакологию. Изучение молекулярных механизмов, обусловливающих лечебные свойства грибов, должно быть в фокусе новых исследований, использующих современные методы и вышеуказанные подходы.

Важным источником терапевтически интересных веществ из ЛШГ может быть пул производимых ими вторичных метаболитов. Эти вещества классифицируются по пяти основным метаболическим путям [16] - интермедиаты биосинтеза шикимовой кислоты для образования ароматических аминокислот, ацетатно-малонатного пути биосинтеза поликетидов из ацетилкоэнзима А, пути биосинтеза стеролов из ацетилкоэнзима А через мевалоновую кислоту, пути синтеза полисахаридов и пептидополисахаридов. Наибольшее разнообразие компонентов содержат пути образования поликетидов и производных мевалоновой кислоты.

Больше усилий необходимо направить на поиск новых источников противораковых препаратов, содержащих низкомолекулярные вторичные метаболиты из ЛШГ, которые ингибируют или запускают специфические клеточные реакции, такие как активация или ингибирование ядерного фактора каппа В $(\mathrm{NF}-k \mathrm{~B})$, тирозинкиназы, ароматазы, сульфатазы, матриксных металлопротеиназ, циклооксигеназ, ДНКтопоизомеразы и ДНК-полимеразы, антиангиогенных веществ и пр. [16, 45-50].

Среди грибных низкомолекулярных веществ, непосредственно влияющих на NF- $k$ B), можно выделить фенэтиловый эфир кофеиновой кислоты (САРЕ), кордиципин, панэпоксидон и циклоэпоксидон. Например, САРЕ, продуцируемый грибами Phellinus linteus и Marasmius oreades, демонстрирует специфическую цитотоксичность по отношению к раковым клеткам и может быть противораковым лекарством, особенно для лечения рака молочной железы $[46,50]$.

Фармацевтические компании, разрабатывающие новые препараты, нуждаются в источниках новых веществ природного происхождения. ЛШГ являются прекрасным неисчерпаемым даром природы, который за короткое время может быть использован для производства новых фармацевтиков.

Ниже представлены 9 этапов открытия новых лекарств из ЛШГ:

1) культивирование грибов и производство биомассы;

2) экстракция биомассы;

3) скрининг грибных экстрактов;

4) проверка эффекта выбранных экстрактов на целевом объекте;

5) химическое фракционирование отобранных экстрактов;

6) определение активных фракций (компонентов), механизма действия и эффективности;

7) действие на подопытных животных;

8) доклинические испытания препарата;

9) клинические испытания.

\section{Нерешенные проблемы в изучении} структурных характеристик, процессов выделения, рецепторных механизмов и противоопухолевой активности ק-глюканов лекарственных грибов

Для успешного использования $\beta$-глюканов и других углеводных полимеров требуются активные исследования по определению взаимосвязей между структурой и активностью грибных углеводородных полимеров, особенно с учетом их молекулярных конформаций и механизмов действия через рецепторы $[25,68]$.

Необходимы исследования роли водорастворимости, размера и молекулярного веса, структуры и молекулярных механизмов действия $\beta$-глюканов с учетом того, что не все $\beta$-глюканы, содержащиеся в ЛШГ, проявляют фармакологическую активность $[22,68,69]$.

До настоящего времени остается неясной зависимость молекулярного веса $\beta$-глюканов от проявляемой ими фармацевтической активности. Недостаточно исследована проблема эффективности высокомолекулярных $\beta$-глюканов по сравнению с низкомолекулярными. Наиболее эффективными являются препараты высокомолекулярных склероглюканов [69]. Однако есть исключения, например, высокую противораковую активность имеет низкомолекулярный Лентинан $[21,22]$. Также следует учитывать различную реактивность $\beta$-глюканов в каждом конкретном случае (реактивность лейкоцитов периферической крови по отношению к $\beta$-глюканам существенно отличается в каждом конкретном случае; реактивность по отношению к $\beta$-глюканам у различных линий мышей значительно варьирует) [22, 68, 69].

Растворимость в воде является одной из наиболее важных характеристик $\beta$-глюканов. До сих пор неизвестно, что именно является определяющим для растворимости и фармацевтической активности $\beta$-глюканов: должны учитываться молекулярный вес, длина цепи, количество боковых цепей; соотношение $(1,4)-,(1,6)-$ и $(1,3)$-связей; ионизация при низком рН 
$[3,22,68]$. Растворимые $\beta$-глюканы проявляют значительно более сильную иммуностимулирующую активность, чем нерастворимые. Причины этого полностью не раскрыты. Неизвестны точные механизмы кишечной абсорбции при пероральном введении $\beta$-глюканов (неспецифическая кишечная абсорбция; прохождение $\beta$-глюканов сквозь щели в кишечном эпителии; абсорбция посредством кишечных М-клеток; абсорбция после связывания с Toll-подобными рецепторными белками со стороны просвета кишечника) $[70,71]$. Возможно, что при пероральном введении нерастворимые $\beta$-глюканы в дальнейшем расщепляются на более мелкие биоактивные олигомеры в ходе переваривания [72].

Необходимо прояснить различия в структуре, растворимости и биологической активности между $\beta$-глюканами из растений $[73,74]$, дрожжей [75] и ЛШГ [3, 22, 25, 68, 69]. Например, структура $\beta$-глюканов зерновых представлена главным образом $\beta$-1,3- и $\beta-1,4-$, но не $\beta-1,6$-связями. В дополнение к этому, растительные $\beta$-глюканы являются линейными, а не разветвленными.

Обычно молекулярный вес растительных $\beta$-глюканов меньше, чем у $\beta$-глюканов из ЛШГ. Биологическая активность $\beta$-глюканов растений еще не полностью изучена. Обычно дрожжевые $\beta$-глюканы лишь частично водорастворимы, но и многие $\beta$-глюканы из ЛШГ не растворимы в воде. Почему они обладают различной биологической активностью? В чем состоит главное преимущество $\beta$-глюканов из ЛШГ по сравнению с таковыми из зерновых или, например, из дрожжей?

Накоплено много сведений о функциях дектина-1 как рецептора $\beta$-глюканов (лектин С-типа, ассоциированный с дендритными клетками) $[25,76,77]$. $\beta$-Глюканы обладают противогрибковой активностью, которая, подобно их противораковой активности, также опосредована связыванием с дектином-1. Однако до сих пор не известно, каким образом происходит это связывание. Еще менее ясны функции дектина-2 [25, 78].

Почему $\beta$-глюканы имеют конформацию тройной спирали, и есть ли у такой структуры преимущества по сравнению с другими веществами из ЛШГ, обладающими однонитевой структурой $[3,22,68,69]$ ? К сожалению, нам не ясно, какие структурные особенности более всего способны обеспечивать специфическую активность и, что даже более важно, как на нее влияет присутствие гидрофильных групп на внешней поверхности спирали. В литературе имеются противоречивые данные о биологической активности тройной спиралевидной и однонитевой структур одних и тех же $\beta$-глюканов, например, у Шизофиллана $[22,68,69]$. До сих пор мы не знаем, где биологическая активность выше - у закрытой или у частично раскрытой тройной спиральной структуры $[28,79]$. Некоторые $\beta$-глюканы с тройными спиралями образуют водные растворы. Однако в условиях щелочного $\mathrm{pH}$ или в присутствии диметилсульфоксида тройная спираль быстро преобразуется в однонитевую, которая при нейтральном $\mathrm{pH}$ постепенно восстанавливается в тройную. Связь между структурой спирали и наблюдаемой иммуномодулирующей и противораковой активностью до сих пор не ясна [25].

\section{Заключение}

Приоритетом в изучении ЛШГ должно стать открытие новых видов шляпочных грибов, обладающих лекарственными свойствами, например, в последние годы были продемонстрированы лекарственные свойства таких видов, как M. oreades, Trametes ochracea, Xylaria nigrepes, Pseudotrameres (=Daedalea) gibbosa, Geastrum saccatum, Cyathus striatus и $C$. olla $[46,82,83]$.

Еще одним приоритетом должна стать разработка новых методов исследования. Например, в 2009 г. в Южной Корее был разработан новый метод экстракции наночастиц водорастворимых $\beta$-глюканов [80]. Также был исследован новый процесс экстракции наночастиц Спарана ( $\beta$-D-глюкан из Sparassis crispa) и Феллиана ( $\beta$-D-глюкан из Phellinus linteus) с использованием технологий нерастворимого карбида вольфрама в качестве наноножа. Это было первое сообщение, продемонстрировавшее, что данный метод приводит к высокому выходу Спарана $(70,2 \%)$ и Феллиана $(65,2 \%)$ со средним размером частиц 150 и 390 нм, соответственно. Авторы предложили использовать метод наноножа для производства $\beta$-D-глюканов в пищевой, косметической и фармакологической промышленности. Немецкие исследователи разработали новый колориметрический метод определения количества $\beta-1,3-1,6-$-глюканов по сравнению с общим содержанием $\beta-1,3$-глюканов и методом определения количества хитина в съедобных грибах [81].

Необходимо провести высококачественные, долгосрочные, двойные слепые, с плацебо в качестве контроля, статистически достоверные, выполненные на большой выборке людей клинические исследования препаратов из ЛШГ для проверки их безопасности и эффективности.

Необходимы дальнейшие исследования роли полисахарид-протеиновых и полисахарид-пептидных комплексов в фармакологической активности препаратов из ЛШГ.

Дополнительные исследования должны продемонстрировать эффективность тех или иных грибных препаратов в лечении конкретных заболеваний, таких как вирусные и бактериальные инфекции, метаболический синдром, раковые заболевания, нарушение регуляции уровня холестерина и т. д.

Для пользы человечества мы должны преодолеть разрыв между западной и восточной медициной. В западной и восточной медицине приняты различные системы правил относительно растительных и грибных препаратов. Большинство западных стран руководствуется правилами для сертифицированных пищевых добавок, в которых и грибные, и растительные компоненты определены как пищевые, не нуждающиеся в клинических испытаниях перед выведением на рынок. Китай наряду с несколькими другими азиатскими странами признает многие травы и некоторые ЛШГ как лекарства, и таким образом в данном случае клинические испытания необходимы. Западная медицина слабо использует препараты из ЛШГ, в основном, из-за их сложной структуры и отсутствия приемлемой фармакологической чистоты. Основной целью в будущем должно стать принятие таких правил, стандартов и практик из западной и восточной медицины, которые окажутся наиболее ценными для здравоохранения в XXI веке [3, 4]. 
Больше внимания следует уделить исследованиям влияния ЛШГ на сельскохозяйственных животных в качестве биомедицинских моделей, для изучения ожирения, диабета, старения, сердечно-сосудистых заболеваний, инфекционных болезней, неврологических расстройств, рака, питания, иммунологии, офтальмологии, репродукции. С другой стороны, мы можем произвести коренной перелом в некоторых отраслях ветеринарии, которые в настоящее время переживают кризис [84], благодаря новым типам продуктов и пищевых добавок, предлагаемых вместо антибиотиков и противовирусных средств для животных.

Следует уделить внимание исследованиям ЛШГ в качестве источников сельскохозяйственных инсектицидов и средств против грибковых и вирусных болезней растений.

Проблемой, требующей большого внимания, является защита интеллектуальной собственности (ИС) генетических ресурсов ЛШГ для внедрения и инноваций. Генетические ресурсы грибов используются в настоящее время в фармацевтической, косметической, сельскохозяйственной, пищевой, ферментной, химической и перерабатывающей промышленностях. Тем не менее, преимущества ИС в современных наукоемких предприятиях часто упускается из виду, несмотря на их потенциал. Задача состоит в том, чтобы создать защиту и извлечь выгоду из активов ИС для изобретений и инноваций $[3,85]$.

Необходимо продолжить информирование общества и потребителей о достижениях науки о ЛШГ.

Сейчас в 2015 г. трудно поверить, что многие люди во всем мире все еще совершенно не осведомлены в этом вопросе, и наша обязанность как ученых состоит в том, чтобы сделать как можно больше для просвещения широких слоев населения о преимуществах использования ЛШГ для здоровья.

\section{Литература/References}

1. Reshetnikov S.V., Wasser S.P., Tan K.K. Higher Basidiomycota as source of antitumor and immunostimulating polysaccharides. Int J Med Mushrooms. 2001;3:361-94.

2. Van Griensven L.J.L.D. Culinary-medicinal mushrooms: must action be taken. Int $\mathrm{J}$ Med Mushrooms. 2009;11:281-86.

3. Wasser S.P. Medicinal mushroom science: history, current status, future trends, and unsolved problems. Int J Med Mushrooms. 2010;12(1):1-16.

4. Chang S.T., Wasser S.P. The role of culinarymedicinal mushrooms on human welfare with a pyramid model for human health. Int $\mathrm{J}$ Med Mushrooms. 2012;1:95-134.

5. Pöder $R$. The Ice man's fungi: facts and mysteries. Int J Med Mushrooms. 2005;7:357-59.

6. Wasson R.G. Soma. Divine Mushroom of Immortality. Harcourt Brace Jovanovich, Inc. NY, 1968.

7. Hyde K.D., Bahkali A.H., Moslem M.A. Fungi - an unusual source for cosmetics. Fungal Diversity. 2010;43:1-9.

8. Lindequist $U$. The merit of medicinal mushrooms from a pharmaceutical point of view. Int J Med Mushrooms. 2013;15(6):517-23.

9. Hawksworth D.L. Mushrooms: the extent of the unexplored potential. Int J Med Mushrooms. 2001;3:333-40.

10. Hawksworth D.L. Global species number of fungi: are tropical studies and molecular approaches contributing to a more robust estimate? Biodivers Conserv. 2012;21:2425-33.

11. Kirk P.M., Cannon P.F., David J.C., Stalpers J.A. Ainsworth \& Brisby's Dictionary of the Fungi. $10^{\text {th }}$ ed. CAB International, Wallingford, 2008.

12. Blackwell $M$. The fungi:1,2,3...5.1 million species? Am J Bot. 2011;98(3):426-38.

13. Bass D., Richards T.A. Three reasons to reevaluate fungal diversity 'on Earth and in the ocean’. Fungal Bio Rev. 2011;25:159-64.
14. Hibbett D.S., Taylor J.W. Fungal systematics: is a new age of enlightenment at hand? Nat Rev Microbiol. 2013;11:129-33.

15. Anke T. Basidiomycetes: a source for new bioactive secondary metabolites. Prog Ind Microbiol. 1989;27:51-66.

16. Zaidman B.-Z., Yassin M., Mahajna J., Wasser S.P. Medicinal mushroom modulators of molecular targets as cancer therapeutics. Appl Microbiol Biotechnol. 2005;67:453-68.

17. De Silva D.D., Rapior S., Sudarman E., Stadler M., Xu J., Alias S.A., Hyde K.D. Bioactive metabolites from macrofungi: ethnopharmacology, biological activities and chemistry. Fungal Diversity. 2013;62:1-40.

18. Dai Y.-Ch., Yang Z.-L., Ui B.-K., Yu Ch.-J., Zhou L.-W. Species diversity and utilization of medicinal mushrooms and fungi in China (review). Int J Med Mushrooms. 2009;11:287-302.

19. Lo H.-Ch., Wasser S.P. Medicinal mushrooms for glycemic control in diabetes mellitus: history, current status, future perspectives, and unsolved problems (review). Int $\mathrm{J}$ Med Mushrooms, 2011;13(5):401-26.

20. Didukh M.Y., Wasser S.P., Nevo E. Medicinal value of species of the family Agaricaceae Cohn (higher Basidiomycetes): Current stage of knowledge and future perspectives. Int $\mathrm{J}$ Med Mushrooms. 2003;5:133-52.

21. Chihara G., Hamuia J., Maeda Y.Y., Arai Y., Fukuoka F. Fractionation and purification of the polysaccharides with marked antitumour activity especially lentinan from Lentinus edodes. Cancer Res. 1970;30:2776-81.

22. Zhang M., Cui S.W., Cheung P.C.K., Wang Q. Antitumor polysaccharides from mushrooms: a review on their isolation, structural characteristics and antitumor activity. Trends Food Sci Technol. 2007; 18:4-19.

23. Zhang Y., Li Sh., Wang X., Zhang L., Cheung P.C.K. Advances in lentinan: isolation, 
structure, chain conformation and bioactivities. Food Hydrocolloids. 2011;25:1996-2006.

24. Zhang Y., Kong H., Fang Y., Nishinan K., Phillips G.O. Schizophyllan: a review on its structure, properties, bioactivities and recent development. Bioactive Carbohydrates and Dietary Fiber. 2013;1(1):53-71.

25. Lee D.H., Kim H.W. Innate immunity induced by fungal b-glucans via dectin-1 signaling pathway. Int J Med Mushrooms. 2014;16(1):1-16.

26. Barillot E., Calzone L., Hupe Ph., Vert J.-Ph., Zinovyev $A$. Computation System Biology of Cancer. CRC Press, Taylor \& Francis Group. A Chapman \& Hall Book; 2013.

27. Stewart B.W., Wild Ch.P., eds. World Cancer Report 2014. Lyon: International Agency for Research on Cancer; 2014.

28. Mizuno T. The extraction and development of antitumor-active polysaccharides from medicinal mushrooms in Japan (Review). Int $\mathrm{J}$ Med Mushrooms. 1999;1:9-29.

29. Hobbs Ch.R. Medicinal value of Lentinus edodes (Berk.) Sing. (Agaricomycetideae). A literature review. Int $\mathrm{J}$ Med Mushrooms. 2000;2:287-302.

30. Zhuang C., Wasser S.P. Medicinal value of culinary-medicinal Maitake mushroom Grifola frondosa (Dicks.:Fr.) S.F. Gray (Aphyllophoromycetideae). Review. Int J Med Mushrooms. 2004;6:287-313.

31. Boh B, Berivic $M$. Grifola frondosa (Diks.:Fr.) S.F. Gray (Maitake mushroom): medicinal properties, active compounds, and biotechnological cultivation. Int $\mathrm{J} \mathrm{Med}$ Mushrooms. 2007;9:89-108.

32. Hobbs Ch.R. The chemistry, nutritional value, immunopharmacology, and safety of the traditional food of medicinal split-gill fungus Schizophyllum commune Fr.:Fr. (Aphyllophoromycetideae). A literature review. Int $\mathrm{J}$ Med Mushrooms. 2005;7:127-40.

33. Lin Z.-B. Lingzhi. From Mystery to Science. Peking University Press. 2009.

34. Mahajna J., Dotan N., Zaidman B.-Z., Petrova R.D., Wasser S.P. Pharmacological values of medicinal mushrooms for prostate cancer therapy: the case of Ganoderma lucidum. Nutrition and Cancer. 2010;61:16-26.

35. Hobbs Ch.R. Medicinal value of Turkey Tail fungus Trametes versicolor (L.:Fr.) Pilát (Aphyllophoromycetideae). Int $\mathrm{J}$ Med Mushrooms. 2004;6:195-218.

36. Mizuno T., Zhuang, Abe K., Okamoto H., Kiho T., Ukai Sh., Leclerc S., Meijer L. Antitumor and hypoglycemic activities of polysaccharides from the sclerotia and mycelia of Inonotus obliquus (Pers.:Fr.) Pil. (Aphyllophoromycetideae). Int J Med Mushrooms. 1999;1:301-316.

37. Balandykin M.E., Zmitrovich I.V. Review on Inonotus obliquus (Basidiomycota). Realm on medicinal applications and approaches on resources estimation. Int $\mathrm{J}$ Med Mushrooms. 2015;17(2):95-104

38. Hsieh P.-W., Wu J.-B., Wu Y.-Ch. Chemistry and biology of Phellinus linteus. BioMed. 2013;3:106-13.
39. Maruyama H., Ikekawa T. Immunomodulation and antitumor activity of a mushroom product, proflamin, isolated from Flammulina velutipes (W.Curt.:Fr.) Singer (Agaricomycetideae). Int J Med Mushrooms. 2007;9:109-22.

40. Matsuzawa T. Studies on antioxidant effects of culinary-medicinal bunashimeji mushroom Hypsizygus marmoreus (Peck) Bigel. (Agaricomycetidae). Int J Med Mushrooms. 2006;8(3):245-50.

41. Holliday H., Cleaver M. Medicinal value of the caterpillar fungi species of the genus Cordyceps (Fr.) Link (Ascomycetes). A review. Int J Med Mushrooms. 2008;10:209-18.

42. Wasser S.P., Didukh M.Y., Amazonas M.A.L.A., Nevo E., Stamets P., Eira A.F. Is widely cultivated culinary-medicinal Royal Sun Agaricus (the Himematsutake mushroom) indeed Agaricus blazei Murrill? Int J Med Mushrooms. 2002;4:267-90.

43. Wasser S.P., Didukh M.Y., Amazonas M.A.L.A., Nevo E., Stamets P., Eira A.F. Is a widely cultivated culinary-medicinal Royal Sun Agaricus (Champignon do Brazil, or the Himematsutake mushroom) Agaricus brasiliensis S.Wasser et al. indeed a synonym of $A$. subrufescens Peck? Int J Med Mushrooms. 2005;7:507-11.

44. Lachter J., Yampolsky Y., Gafni-Schieber R., Wasser S.P. Yellow brain culinary-medicinal mushroom, Tremella mesenterica Ritz.: Fr. (Higher Basidiomycetes), is subjectively but not objectively effective for eradication of Helicobacter pylori; a prospective controlled trial. Int J Med Mushrooms. 2012;14 (1):55-63.

45. Yassin M., Wasser S.P., Mahajna J. Substances from the medicinal mushroom Daedalea gibbosa inhibit kinase activity of native and T315I mutated Bcr-Abl. Int J Oncol. 2008:32:1197-1204.

46. Petrova R.D., Mahajna J., Wasser S.P. et al. Marasmius oreades substances block NF-kappaB activity through interference with IKK activation pathway. Mol Biol Rep. 2009;36:737-44.

47. Rouhana-Toubi A., Wasser S.P., Fares F. Ethyl acetate extracts of submerged cultured mycelium of higher Basidiomycetes mushrooms inhibit human ovarian cancer cell growth. Int J Med Mushrooms. 2009;11: 29-37.

48. Dotan N., Wasser S.P., Mahajna J. The culinary-medicinal mushroom Coprinus comatus as a natural antiandrogenic modulator. Integrative Cancer Therapies. 2011;10(2):148-59.

49. Ruimi N., Petrova R.D., Agbaria R., Sussan S., Wasser S.P., Reznick A.Z., Mahajna J. Inhibition of TNF $\alpha$-induced iNOS expression in HSVtk transduced 9L glioblastoma cell lines by $M a-$ rasmius oreades substances through $\mathrm{NF}-\kappa \mathrm{B}$ - and MAPK-dependent mechanisms. Mol Biol Rep. 2010;37:3801-12.

50. Ruimi N., Rwashdeh H., Wasser S.P., Konkimalia B., Efferth T., Borgatti M., Gambari $R$., Mahajna J. Daedalea gibbosa substances inhibit LPS-induced expression of iNOS by suppression of NF- $\kappa$ B and MAPK activities in RAW 264.7 macrophage cells. Int J Mol Med. 2010;25:421-32.

51. Boh B. Ganoderma lucidum: a potential for biotechnological production of anti-cancer and immunomodulatory drugs. Recent Patents on Anticancer Drug Discovery. 2013;8:255-87. 
52. Wasser S.P., Zmitrovich I.V., Didukh M.Y., Spirin W.A., Malysheva V.F. Morphological Traits of Ganoderma lucidum Complex Highlighting $G$. tsugae var. jannieae: The Current Generalization. Ruggell, Liechtenstein, A.R.A. Gantner Verlag K.$\mathrm{G} ; 2006$.

53. Moncalvo J.-M., Rivarden L. A nomenclatural study of the Ganodermataceae Donk. Synopsis Fungorum. 1997;11:1-114.

54. Zhao J.-D. The Ganodermataceae in China. Bibliotheca Mycologica Ser. 132. Berlin, Stuttgart J. Cramer; 1989.

55. Cao Y., Wu Sh.-H., Dai Yu.-Ch. Species clarification of the prize medicinal Ganoderma mushroom "Lingzhi". Fungal Diversity. 2012;56:49-62.

56. Yang Z.L., Feng B. What is the Chinese "Lingzhi"? - a taxonomic mini-review. Mycology. 2013;4(1):1-4.

57. Chen Sh., Xu J., Liu Ch. et al. Genome sequence of the model medicinal mushroom Ganoderma lucidum. Nate Communications 2012;3:913/DOI:10.10/ncomms192338.

58. Kerrigan R. Agaricus subrufescens, a cultivated edible and medicinal mushroom, and its synonyms. Mycologia. 2005;97:12-24.

59. Wasser S.P. Molecular identification of species of the genus Agaricus. Why should we look at morphology? Int J Med Mushrooms. 2007;9:85-8.

60. Buchalo A.S., Mykchaylova O., Lomberg M., Wasser S.P. Microstructures of vegetative mycelium of macromycetes in pure culture. Kiev: Alterpress; 2009.

61. McKenna D.J., Jones K., Hughes K., Humphrey Sh. Botanical Medicines. The Desk Reference for Major Herbal Supplements. 2nd edn. NY, London, Oxford: The Haworth Herbal Press; 2002.

62. Deng G., Lim H., Seidman A. et al. A phase I/II trial of a polysaccharide extract from Grifola frondosa (Maitake mushroom) in breast cancer patients: immunological effects. J Cancer Res Clin Oncol. 2009;135:1215-21.

63. Ishibashi K.I., Dogasaki C., Iriki T., Motoi M., Kurone Y.I., Miura N.N., Adachi L.S., Ohno N. Anti- $\beta$-glucan antibody in bovine sera. Int J Med Mushrooms. 2005;7:513.

64. Li JW.-H., Vederas J.C. Drug discovery and natural products: end of an era or an endless frontier. Science. 2009;325:161-5.

65. Ammerpohl O., Tiwari S., Kalthoff H. Target gene discovery for novel therapeutic agents in cancer treatment. Methods Mol Biol. 2010;576:42745.

66. Pollack $A$. Drug firms see fortune in treating cancer. Int Herald Tribune. 2009;15-6.

67. Endo $A$. The origin of the statins. Int Congress Series. 2004;1262:3-8.

68. Chen J., Seviour R. Medicinal importance of fungal $\beta-(1-3)$, (1-6)-glucans. Mycol Res. 2007;111:635-52.

69. Ohno N. Structural diversity and physiological functions of $\beta$-glucans. Int J Med Mushrooms. 2005;7:167-73
70. Miller H., Zhang J., Kuo Lee R., Patel G.B., Chen $W$. Intestinal $M$ cells: the fallible sentinels? World J Gastroenterol. 2007;14:1477-86.

71. Pamer E.G. Immune responses to commensal and environmental microbes. Nat Immunol. 2007;8:1173-78.

72. Lehmann J., Kunze R. Water-soluble low molecular weight beta-glucans for modulating immunological responses in mammalian system. US Patent 2000; 6143883.

73. Tada R., Adachi Y., Ishibashi K-I., Tsubaki K., Ohno N. Binding capacity of a barley $\beta$-Dglucan to the b-glucan recognition molecule Dectin-1. J Agr Food Chem. 2008;56:1442-50.

74. Tiwari U., Cummins E. Factors influencing beta-glucan levels and molecular weight in cereal-based products. Cereal Chem. 2009;86:290-301.

75. Liu J.J., Gunn L., Hansen R., Yan J. Combined yeast-derived beta glucan with anti-tumor monoclonal antibody for cancer immunotherapy. Exper Mol Pathol. 2009;86:208-14.

76. Taylor P.R., Tsoni S.V., Willment J.A. et al. Dectin-1 is required for beta-glucan recognition and control of fungal infection. Nat Immunol. 2007;8:31-8.

77. Harada T., Ohno N. Dectin-1 and GM-CSF on immunomodulating activities of fungal 6-branched 1,3-b-glucans. Int J Med Mushrooms. 2008;10:101-4.

78. Graham L.M., Brown G.D. The Dectin-2 family of C-type lectins in immunity and homeostasis. Cytokine. 2009;48:148-55.

79. Falch B.H., Espevik T., Ryan L., Stokke B.T. The cytokine stimulating activity of (1-3)-betaD-glucans is dependent on the triple helix conformation. Carbohydr Res. 2000;329:587-96.

80. Park H.-G., Shim Y.Y., Choi S.-O., Park W.-M. New method development for nanoparticle extraction of water-soluble $\beta$-(1-3)-D-glucan from edible mushrooms, Sparassis crispa and Phellinus linteus. Agricultural and Food Chem. 2009; 57:2147-54.

81. Nitschke J., Modick H., Busch M., Wantoch R., Wantoch von Rekowski R., Albenbach H.-J., Mölleken H. A new colorimetric method to quantify $\beta-1,3-1,6$-glucans in comparison with total $\beta$-1,3-glucans in edible mushrooms. Food Chem. 2011;127:791-6.

82. Khamaisie H., Sussan S., Tal M., Najajren Y., Rurhardt M., Mahajna J. Oleic acid is the active component in the mushroom Daedalea gibbosa inhibiting Bcr-Abl kinase autophosphorylation activity. Anticancer Res. 2011;31:177-4.

83. Sharvit L.E., Wasser S.P., Fares F. The effect of culture liquid ethyl acetate mycelium extracts of medicinal mushrooms on the viability of human pancreatic cancer cells. Int J Med Mushrooms. 2012;14 (2):169-80.

84. Roberts R.M., Smith G.W., Bazer F.W. et al. Farm animal research in crisis. Science. 2009;324:468-9.

85. Jong Sh.-J. Protecting intellectual property assets of mushroom genetic resources for invention and innovation. Int J Med Mushrooms. 2005;7 (3):348-9. 